\title{
Proceeding
}

9th INSHS International Christmas Sport Scientific Conference, 4-6 December 2014. International Network of Sport and Health

Science. Szombathely, Hungary

\section{Injury risks of heading in young football players}

\author{
MILOŠ LUKÁŠEK $\triangle$, MIRIAM KALICHOVÁ \\ Faculty of Sport Studies, Masaryk University, Brno, Czech Republic
}

\begin{abstract}
Lukášek, M., \& Kalichová, M. (2015). Injury risks of heading in young football players. J. Hum. Sport Exerc., 9(Proc1), pp.S490-S499. The aim of the research is to contribute to findings concerning increasingly acute problems connected with heading in football. Unlike most of available studies where heading with adults is dealt with, our study focuses primarily on heading with children. 16 children aged 10, weighing $36.2 \pm 4.7$ $\mathrm{kg}$ took part in the research. Each tested person executed headings of a ball dropped from $0 \mathrm{~m}(3.13 \mathrm{~m} / \mathrm{s})$, $1 \mathrm{~m}(4.43 \mathrm{~m} / \mathrm{s})$ and $1,5 \mathrm{~m}(5.43 \mathrm{~m} / \mathrm{s})$ ie. 3 headings in total. The total number of tests was 48 . A triaxial accelerometer $(1000 \mathrm{~Hz})$ was used in the measurements. As presumed, with increasing drop-height the head acceleration increased on impact. With drop-height of $0.5 \mathrm{~m}$ we recorded $59.4 \pm 15.8 \mathrm{~m} \cdot \mathrm{s}-2$, with $1 \mathrm{~m}$ we measured $76.4 \pm 15 \mathrm{~m} \cdot \mathrm{s}-2$ and $100.1 \pm 25 \mathrm{~m} \cdot \mathrm{s}-2$ from $1.5 \mathrm{~m}$. These acceleration values do not pose danger if individual, however, we came to conclusion that repeated impacts, especially those of higher speed, may lead to functional problems of a child's brain. Key words: ACCELEROMETRY, FOOTBALL, HEAD, CHILD
\end{abstract}

\footnotetext{
Corresponding author. Masarykova univerzita, Kamenice 5, 60500 Brno, Czech Republic

E-mail: lukasek@fsps.muni.cz

9th INSHS International Christmas Sport Scientific Conference, 4-6 December 2014. International Network of Sport and

Health Science. Szombathely, Hungary.

JOURNAL OF HUMAN SPORT \& EXERCISE ISSN 1988-5202

(c) Faculty of Education. University of Alicante

doi:10.14198/jhse.2015.10.Proc1.43
} 


\section{INTRODUCTION}

Lately, many authors stress, besides improving the performance of heading, the issues of health concern in sports. In football, there is an increased concern with ball heading and its influence on brain functions. This specific game feature is a regular part of trainings and matches. As previous studies suggest, the average number of headings during football matches has significantly increased in last twenty years. Studies by Smodlaka (1984) and Sortland and Tysvaer (1989) state that on average rate the footballer uses heading 5-6 times during matches. Later studies raise this number up to 6-12 on average (Levy et al., 2012; Spiotta et al., 2012; Matser et al., 1999), some suggest even 16 headings an average match (Rutherford et al., 2005). A sum of 10 headings must be added to the average rate, if we include trainings (Rutherford et al., 2003). A professional football player experiences a median of 800 heading occasions every season (Levy et al., 2012). Lipton et al. (2013) have discovered a threshold level of approximately 885 to 1550 headings per year, in which exceeding this threshold will cause the fractional anisotropy values to decrease significantly. A conclusion that emerges from this data is that heading poses considerable dynamic strain to the head of a footballer and needs to be examined thoroughly.

These impacts individually do not amount to such level to become a cause of a concussion. This statement may be supported by a fact that with proper technique typical normal heading by adult players generates $\mathrm{HIC}$ values less than $0.1 \%$ of that required to produce brain injury in a single impact (Babbs, 2001). However, repeated subclinical effects of heading may compound over time, resulting in neurological deficits (Mehnert et al., 2005; Dezman et al., 2013; Taha et al., 2013). Rutherford et al. (2003) hypothesized that in football, cumulative effects similar to those described in boxing could occur. Some authors argued that impacts to the head while playing soccer, caused by heading, can be massive enough to lead to mild traumatic brain injury characterized by neck ache, vegetative symptoms or a decline in neuropsychological test performance, and brief changes of consciousness (Rutherford \& Stephens, 2007). Symptoms of mild traumatic brain injury fade away quickly in most cases, nevertheless, long-term repetitive strain may induce permanent health problems (Gronwall \& Wrightson, 1975; Rieder \& Jansen, 2011). Neuropsychological literature puts it that permanent mild head injury results in a structural damage that can be detected via neuropsychological tests (Elson \& Ward 1994; Goodman, 1994). Rutherford et al. (2003) mention two causes of cumulative injuries in football. In the first case, there may be a residual effect of concussive injury that increases as the number of such injuries rises, especially when a latter acute injury occurs before the previous one has healed up. The second cause of cumulative head trauma in football are small, subliminal yet frequent impacts that do not cause concussive injuries themselves. They lead to microtraumatic injuries causing chronic brain damage. According to Lynch and Bauer (1996), injury depends more on the acceleration of the head than on the applied force. Naunheim et al. (2003) specify that high angular acceleration is more threatening than linear acceleration.

The head acceleration during football heading is influenced by number of factors. Comparing novices and adult footballers Kerr \& Riches (2004) concluded that differences in neck muscle coordination may be responsible for higher acceleration during heading by novices. A similar conclusion was submitted by Dezman et al. (2013), ie. the neck strength difference was positively correlated with angular head acceleration (rho $=0.497 ; P=0.05$ ), with a trend toward significance for linear head acceleration (rho = 0.485; $P=0.057$ ). Tysvaer \& Storli (1981) provide an additional statement that when soccer players are prepared to head the ball and they contact the ball properly, the effects of the impact force are effectively reduced by the musculotendinous structures in the neck. According to Mehnert et al. (2005) it is still not definite how much of the force of impact received by the head is conveyed to the soft tissue structures of the neck, or how much is dissipated by the neck muscles and transmitted to the bony structures and joints 
of the cervical spine. Another factor which correlates with increasing angular and linear acceleration is the mass ratio of the ball to a player's head (Queen et al., 2003). We may conclude that women and especially children are exposed to greater risks of injury in heading. Babbs (2001) that not even use of a smaller, size 4 ball does not adequately compensate for the smaller effective mass of younger players. Another potential risk factors influencing acceleration are heading technique, the mass, size, horizontal speed, and inflation pressure of the ball, and the effective mass and speed of the player (Babbs, 2001; Bauer et al., 2001; Erkmen, 2009).

Modeling and measuring head acceleration has been carried out in adult footballer by most authors (Babbs, 2001; Naunheim et al., 2003; Taha et al., 2013; and others). Novices and youngsters has been lately covered by only a minority of authors such as Babbs (2001), Queen et al. (2003), Riches (2005) or Hanlon et al. (2012). In particular, children learning the game have a greater head-to-ball size ratio and lower neck strength, putting them at risk for head injury (Queen et al., 2003; Riches, 2005). Based on these facts The American Youth Soccer Organization (AYSO) does not recommend heading below the age of ten. (Ouellette, 2014). Stephens et al. (2005) studied if minor head injuries in football heading have connection to neuropsychological function of adolescent footballers. By means of neuropsychological tests they arrived at conclusion that heading does not have any influence on worsening these functions. These result, however, differ from neuropsychicologocal literature which states that repeated minor head injuries results in structural damage, tracable in neuropsychic tests (Elson \& Ward 1994; Goodman, 1994).

In our opinion the existing findings concerning the health issues of heading in children and youths are insufficient. On that account we wish to contribute to deeper knowledge of these findings. With accelerometry we aim to establish kinetic parameters of an impact of a ball on a head to find out more about the risks to developing organism of children.

\section{MATERIAL AND METHODS}

\section{Participants}

The research sample consisted of 16 youth footballers (U 11) aged ten on average. The average weight was $36.2 \pm 4.7 \mathrm{~kg}$. These boys practice twice a week for three hours. The tested persons have been practicing for three years on average.

\section{Measures}

We constructed a triaxial accelerometer and gyroscope (fig. 1) at the Faculty of Sport Studies for measurements. It is capable of collecting data at $1000 \mathrm{~Hz}$ and store it on mini SD card with measuring capacty of 70 hours. The range is $\pm 16 \mathrm{~g}$ and it enables to measure rotation $2000 \% \mathrm{sec}$ per axis. The size of our accelerometer $(60 \times 38 \times 16 \mathrm{~mm})$ along with its low weight does not restrict or bother sportsmen, nor children, during their performance and makes it ideal for measuring in real-life conditions while in training as well as in competitions.
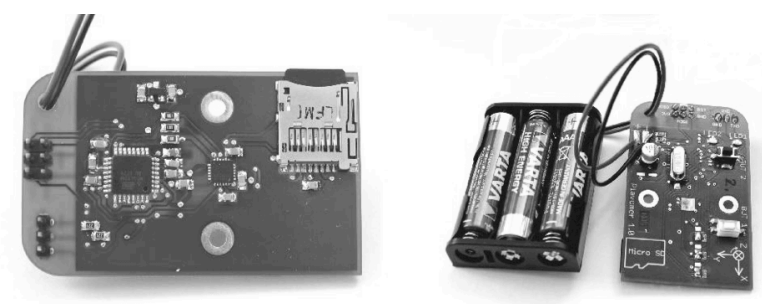

Figure 1. Triaxial accelerometer and gyroscope 


\section{Procedures}

The testing took place indoors during regular afternoon training session. A size 4, FIFA quality tested ball was used during the procedure. First the height of the tested person was measured and consequently the ball was dropped from the required height on the tested persons head. Each tested person executed headings of a ball dropped from $0.5 \mathrm{~m}(3.13 \mathrm{~ms}-1), 1 \mathrm{~m}(4.43 \mathrm{~ms}-1)$ and $1.5 \mathrm{~m}(5.43 \mathrm{~ms}-1)$ ie. 3 headings in total. The total number of attempts was 48.

\section{Analysis}

From the measurements taken we first evaluated the figures of maximum acceleration during the impact of the ball to the head. Consequently, the elapsed time of individual phases was measured. Given the data were normally distributed we used Pearson correlation coefficient to establish the relations between variables measured. To predict the acceleration we established regression lines in the graphs.

\section{RESULTS}

From the data measured we were mainly interested in values of horizontal acceleration of a head and time characteristics to which the function of this variable relates. Fig. 2 shows the typical value course of horizontal acceleration of the head during the impact of a ball with vertical velocity of $3.13 \mathrm{~m} \cdot \mathrm{s}-1$ (green curve), $4.43 \mathrm{~m} \cdot \mathrm{s}-1$ (blue curve) a $5.43 \mathrm{~m} \cdot \mathrm{s}-1$ (red curve).

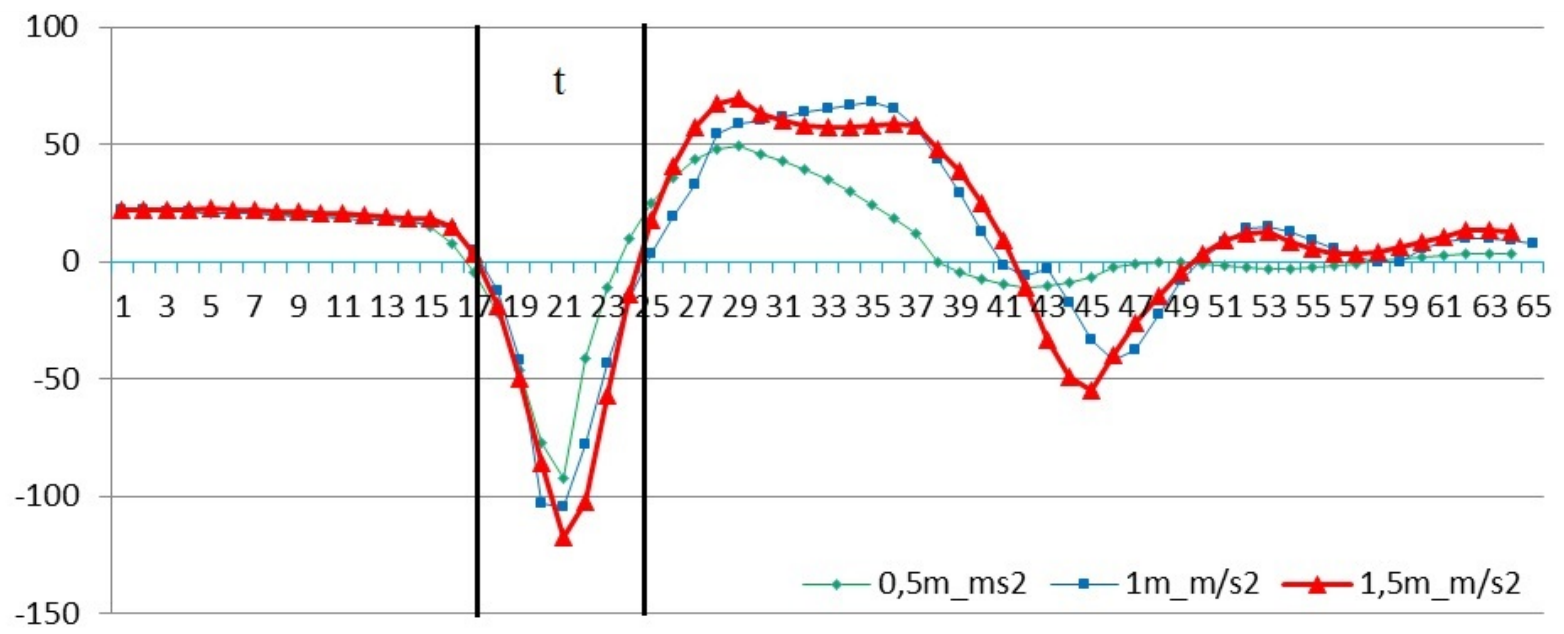

Figure 2. Typical curve acceleration of a head on contact with a ball with vertical velocity $3.13 \mathrm{~m} \cdot \mathrm{s}-1$ (green curve), $4.43 \mathrm{~m} \cdot \mathrm{s}-1$ (blue curve) a $5.43 \mathrm{~m} \cdot \mathrm{s}-1$ (red curve)

From the whole course of the curve we focused mainly on the time sequence marked by two verticals in the graph. This is the instance when the forward motion of a head is slowed down by the impact of a ball. The figures of maximum horizontal acceleration measured are shown in the table 1. 
Table 1. Values of maximum horizontal acceleration and when contacting the ball falling from $0.5 \mathrm{~m}, 1$ $\mathrm{m}$ a $0.5 \mathrm{~m}$

\begin{tabular}{ccccc}
\hline tested person & weight/ $\mathrm{kg}$ & $\mathrm{a} \max / \mathrm{m} \cdot \mathrm{s}-20.5 \mathrm{~m}$ & $\mathrm{a} \max / \mathrm{m} \cdot \mathrm{s}-2 \mathrm{~m}$ & $\mathrm{a} \max / \mathrm{m} \cdot \mathrm{s}-21.5 \mathrm{~m}$ \\
\hline 1 & 34.6 & 94.429 & 104.605 & 117.418 \\
2 & 42.6 & 67.142 & 82.393 & 101.731 \\
3 & 30.2 & 45.309 & 65.854 & 76.65 \\
4 & 36.3 & 42.416 & 84.448 & 102.32 \\
5 & 35.1 & 39.302 & 62.262 & 90.968 \\
6 & 42213 & 60.602 & 71.146 & 74.413 \\
7 & 42155 & 50.53 & 52.116 & 130.538 \\
8 & 36.9 & 88.256 & 113.755 & 154.555 \\
9 & 41.9 & 43.69 & 60.905 & 69.499 \\
10 & 42247 & 64.967 & 74.768 & 80.736 \\
11 & 43.8 & 49.922 & 72.66 & 61.221 \\
12 & 37.6 & 50.501 & 77.168 & 100.217 \\
13 & 32.6 & 53.941 & 73.8 & 84.731 \\
14 & 32.7 & 73.982 & 68.761 & 102.545 \\
15 & 41.3 & 71.822 & 73.799 & 130.313 \\
16 & 41.8 & 52.987 & 83.337 & 123.037 \\
\hline average & 36.213 & 59.362 & 76.361 & 100.056 \\
\hline SD & 4.702 & 15.763 & 14.995 & 24.996 \\
\hline
\end{tabular}

With increasing velocity of the ball hitting against the head the values of average acceleration increase correspondingly. The ball velocity $3.13 \mathrm{~m} \cdot \mathrm{s}-1$ corresponds with average value of head acceleration a = $59.4 \pm 15.8 \mathrm{~m} \cdot \mathrm{s}-2$, when minimum was $-39.3 \mathrm{~m} \cdot \mathrm{s}-2$, maximum $-94.4 \mathrm{~m} \cdot \mathrm{s}-2$, which corresponds with variance of dispersion $\mathrm{R}=55.1 \mathrm{~m} \cdot \mathrm{s}-2$. Ball velocity $4.43 \mathrm{~m} \cdot \mathrm{s}-1$ corresponds with average acceleration $\mathrm{a}=-76.4 \pm 15$ $\mathrm{m} \cdot \mathrm{s}-2$, recorded minimum was $-52.1 \mathrm{~m} \cdot \mathrm{s}-2$, maximum $-113.8 \mathrm{~m} \cdot \mathrm{s}-2$, hence $\mathrm{R}=61.7 \mathrm{~m} \cdot \mathrm{s}-2$. For ball velocity $5.43 \mathrm{~m} \cdot \mathrm{s}-1$ we measured $\mathrm{a}=-100.1 \pm 25 \mathrm{~m} \cdot \mathrm{s}-2$, minimum $-61.2 \mathrm{~m} \cdot \mathrm{s}-2$, maximum $154.6 \mathrm{~m} \cdot \mathrm{s}-2$, hence $\mathrm{R}=$ $93.4 \mathrm{~m} \cdot \mathrm{s}-2$. Gradually, the average acceleration increased from $6 \mathrm{~g}$ to $8 \mathrm{~g}$ and consequently to $10 \mathrm{~g}$. We noted that variance of dispersion increases along with average value of acceleration.

In table 2 there are time characteristics of the impact phase. For individual ball velocities $t 1$ equals gradually $3.9 \mathrm{~ms}, 5.1 \mathrm{~ms}$ a $4.7 \mathrm{~ms}$, t2 equals gradually $3.4 \mathrm{~ms}, 3.5 \mathrm{~ms}$ a $3.8 \mathrm{~ms}$. 
Table 2. Time characteristics of ball impact, $\mathrm{t} 1$ - elapsed time of head deceleration from $\mathrm{a}=0$ to max. a, $\mathrm{t} 2$ - elapsed time of head deceleration max. a to $\mathrm{a}=0, \mathrm{t}=\mathrm{t} 1+\mathrm{t} 2$

\begin{tabular}{|c|c|c|c|c|c|c|c|c|c|}
\hline Tested & $\mathrm{t} 1 / \mathrm{ms}$ & $\mathrm{t} 2 / \mathrm{ms}$ & $\begin{array}{l}t=t 1 \\
+t 2\end{array}$ & $\mathrm{t} 1 / \mathrm{ms}$ & $\mathrm{t} 2 / \mathrm{ms}$ & $\begin{array}{l}t=t 1 \\
t+2\end{array}$ & $\mathrm{t} 1 / \mathrm{ms}$ & $\mathrm{t} 2 / \mathrm{ms}$ & $\begin{array}{l}t=t 1 \\
t+2\end{array}$ \\
\hline person & $\begin{array}{c}\text { a0- } \\
\text { amax }\end{array}$ & $\begin{array}{c}\text { amax- } \\
\text { a0 }\end{array}$ & $/ \mathrm{ms}$ & $\begin{array}{c}\text { a0 - } \\
\text { amax }\end{array}$ & $\begin{array}{c}\text { amax- } \\
\text { a0 }\end{array}$ & $/ \mathrm{ms}$ & $\begin{array}{c}\mathrm{a} 0 \text { - } \\
\mathrm{amax}\end{array}$ & $\begin{array}{c}\text { amax- } \\
\text { a0 }\end{array}$ & $/ \mathrm{ms}$ \\
\hline & $0.5 \mathrm{~m}$ & $0.5 \mathrm{~m}$ & $0.5 \mathrm{~m}$ & $1 \mathrm{~m}$ & $1 \mathrm{~m}$ & $1 \mathrm{~m}$ & $1.5 \mathrm{~m}$ & $1.5 \mathrm{~m}$ & $1.5 \mathrm{~m}$ \\
\hline 1 & 3 & 3 & 6 & 4 & 3 & 7 & 5 & 3 & 8 \\
\hline 2 & 5 & 5 & 10 & 5 & 4 & 9 & 5 & 4 & 9 \\
\hline 3 & 3 & 3 & 6 & 3 & 4 & 7 & 4 & 4 & 8 \\
\hline 4 & 5 & 4 & 9 & 6 & 3 & 9 & 4 & 4 & 8 \\
\hline 5 & 3 & 4 & 7 & 5 & 4 & 9 & 5 & 3 & 8 \\
\hline 6 & 5 & 3 & 8 & 5 & 4 & 9 & 5 & 4 & 9 \\
\hline 7 & 6 & 3 & 9 & 4 & 3 & 7 & 4 & 4 & 8 \\
\hline 8 & 6 & 3 & 9 & 6 & 4 & 10 & 5 & 5 & 10 \\
\hline 9 & 4 & 4 & 8 & 6 & 3 & 9 & 6 & 3 & 9 \\
\hline 10 & 4 & 4 & 8 & 5 & 3 & 8 & 5 & 5 & 10 \\
\hline 11 & 3 & 3 & 6 & 5 & 3 & 8 & 5 & 2 & 7 \\
\hline 12 & 4 & 4 & 8 & 5 & 4 & 9 & 5 & 4 & 9 \\
\hline 13 & 3 & 3 & 6 & 5 & 2 & 7 & 5 & 4 & 9 \\
\hline 14 & 3 & 3 & 6 & 5 & 4 & 9 & 3 & 4 & 7 \\
\hline 15 & 3 & 3 & 6 & 5 & 3 & 8 & 4 & 4 & 8 \\
\hline 16 & 3 & 3 & 6 & 7 & 5 & 12 & 5 & 3 & 8 \\
\hline average & 3.938 & 3.438 & 7.375 & 5.063 & 42127 & 8.562 & 4.688 & 27454 & 8.438 \\
\hline SD & 1.088 & 0.609 & 1.323 & 0.899 & 0.707 & 1.273 & 0.682 & 0.75 & 0.838 \\
\hline
\end{tabular}

The results (fig. 3) suggest that elapsed time $\mathrm{t} 1$ (blue) during which a head reaches from zero acceleration to maximum value of acceleration does not increase nor decrease related to the ball velocity ie. the height from which the ball was falling. The same applies to phase t2 (green) during which the maximum acceleration decreases back to zero value. The whole elapsed time $t$ (red) in heading during which the head decelerates the forward motion was $7.4 \mathrm{~ms}, 8.6 \mathrm{~ms}$ and $8.4 \mathrm{~ms}$ for each of the individual impacts. For the least velocity the time elapsed was also the shortest, nevertheless, for the other two velocities the time of deceleration was nearly the same. 


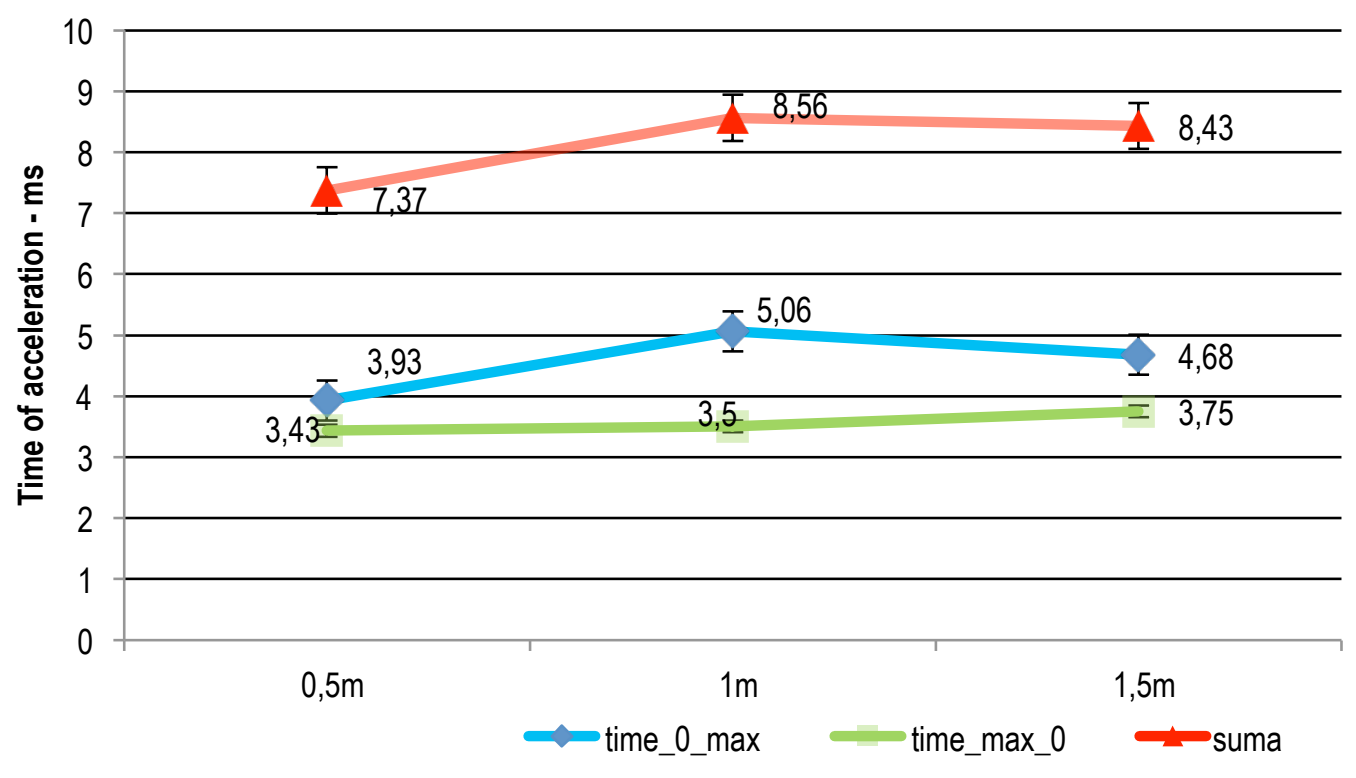

Figure 3. The time characteristics of the phase of the head deceleration on the impact of a ball $\mathrm{t}_{1}$ (blue), $\mathrm{t}_{2}$ (green), $\mathrm{t}$ (red)

\section{DISCUSSION}

The head of a young footballer reached negative acceleration $6-10 \mathrm{~g}(\mathrm{~g}=9.81 \mathrm{~m} \cdot \mathrm{s}-2)$ on the impact of a ball with vertical speed $3.13-5.43 \mathrm{~m} \cdot \mathrm{s}-1$. These results may be compared with data of Taha et al. (2013) who carried out modeling and measuring head acceleration on the impact of a ball falling from $0.5 \mathrm{~m}, 1 \mathrm{~m} \mathrm{a}$ $1.5 \mathrm{~m}$ and their findings result in acceleration of approximately $4 \mathrm{~g}, 5 \mathrm{~g}$ and $6 \mathrm{~g}$. Our slightly higher figures may be on account of children being used as a research sample as the Taha et al. research focused on adults. Babbs (2001) states that an average horizontal velocity of a ball being headed by players aged 9 13 is $7.1 \mathrm{~m} \cdot \mathrm{s}-1$. Additionally, the higher accelerations for youth players are in the range 15 to $20 \mathrm{~g}$ when unlucky combinations of high ball velocity, high inflation pressure, and bad technique occur. Let us take into account the figures of head acceleration, despite the fact the ball had zero horizontal velocity; only the vertical velocity contributed to the impact. With increasing ball speed of course increases the head acceleration. On this bases we presume that a ball reaching horizontal velocity around $7 \mathrm{~m} \cdot \mathrm{s}-1$ similar, or perhaps higher, acceleration could be reached. Hanlon \& Bir (2011) figure in 13 year old girls show horizontal acceleration between $4.5-62.9 \mathrm{~g}$, which makes $20.4 \mathrm{~g}$ on average which is comparable to Schewchenko et al. (2005) who state figure $19.8 \mathrm{~g}$ which would be the presumed increase in acceleration of our tested sample. As Funk et al. (2011) claims, statistical analysis of head impact data from football players suggests that head accelerations of $80 \mathrm{~g}$ and $6000 \mathrm{rad} \cdot \mathrm{s}-2$ pose less than a $1 \%$ risk of concussion. It is obvious, that our acceleration figures in heading balls flying at average speed, nor the presumed ones, do not pose danger to the brain if executed individually. However, it is still unclear what would repetitive impacts lead to.

Most authors do not show figures related to time elapsed through the impact, nor do they state further time characteristics. To establish a negative influence on the brain we need to acquire not only the acceleration figures, but also the elapsed time of an impact (Prasad \& Mertz, 1993; Naunheim et al., 2003). Our figures 
suggest that the head deceleration lasted $8.1 \mathrm{~ms}, 4.6 \mathrm{~ms}$ was the period needed for the head to reach maximum deceleration, $3.5 \mathrm{~ms}$ was the time it took the head to come from maximum deceleration to full stop. These figures are, comparing to $25 \mathrm{~ms}$ (the initial acceleration pulses) and $15 \mathrm{~ms}$ (the peak linear acceleration) as Naunheim et al. (2003) state them, relatively low. We presume that the cause lies in stronger impacts $(16 \mathrm{a} 20 \mathrm{~g})$ used in this study. Other authors state the duration of impact in the range in the range of 10 ms to 23 ms (Lynch \& Bauer, 1996; Tysvaer, 1992; Schneider \& Lichte, 1975). If we add time of the following phase of impact, lasting $14 \mathrm{~ms}$ during which the head employs the forward motion again, to our $8.1 \mathrm{~ms}$ we come down to $22 \mathrm{~ms}$ which bears comparison to the authors mentioned above.

Apart from figures of chosen variables also the relation between them was put to examination. Through the medium of Pearson correlation coefficient we established the relations between weight of the tested persons, velocity of the ball, head acceleration, and time characteristics of impacts. In most cases no statistically significant relation on level 0.05 was found. No relation between times 11 and $t 2$, nor the whole time t was established. Also relation between the ball velocity and time characteristics of the head forward motion decrease proved insignificant. No relation between the weight of the tested persons and the time characteristics of the impact, nor between weight and head acceleration. We presumed to establish statistic pattern of increased weight of a player and decreased negative head acceleration during the impact. On the grounds of literature and logical assumption we explain this occurrence by presence of various factors. It is not only the bodyweight that contributes to heading motion. It is the strength of neck muscles what chiefly influences the whole performance (Kerr \& Riches, 2004; Dezman et al., 2013). As we expected, the differences in neck musculature in 10 year olds varies a lot as very different anthropometric characteristics and body postures, observed during the testing, suggest. Furthermore, the technique of heading, which is still undeveloped in young footballers, is also decisive factor (Babbs, 2001; Erkmen, 2009). No statistical relation was established between acceleration and times $\mathrm{t} 1 \mathrm{a}$ t2 and $\mathrm{t}$. On the other hand, the relation between maximum head accelerations between individual velocities of the ball. For relation between amax 0.5 and amax 1 the correlation coefficient $r=0.71$ was established, for relation between amax 1 and amax1.5 $r=0.51$ a relation between amax 0.5 and amax $1.5 r=0.54$. The relations between these statistical significances suggests individual responses in particular players to standard, not straining velocities of a falling ball. This may be due to mastering the technique of heading, strengthening the neck musculature, experience, concentration or alertness.

\section{CONCLUSIONS}

The purpose of this study was firstly to confirm suitability of measuring acceleration with our constructed accelerometer. Given the acquired data are comparable with previously published figures, we consider this accelerometer suitable for further, more complex measurements in this area.

Secondly, we pursued to establish whether in footballers during rapid physical development substantial criteria typical for heading as this is one of the very common football features. It was not our aim to acquire maximum figures of the head acceleration. We rather aimed to learn about the gradually growing tendency of acceleration figures and how the elapsed time of these changes. The acquired acceleration values do not pose danger if individual, however, we came to conclusion that repeated impacts, especially those of higher speed, may lead to functional problems of a child's brain.

We also conclude it is chiefly the heading technique that has the greatest influence over the heading performance as the level varied among the persons within the sample group, along with development of neck musculature. From this point the sample group seems rather not homogeneous. To confirm this 
theory we would, however, need more individual characteristics of players, carry out more measurements and consequently compare the figures intra- and interindividually. This study shall be a starting point for further research in children and youths.

This project has approval from the ethics committee Masaryk University (No. 4/2014). This research was supported by the Specific research grant of Masaryk University MUNI/A/0875/2013.

\section{REFERENCES}

1. Babbs, F. (2001). Biomechanics of Heading a Soccer Ball: Implications for Player Safety. The Scientific World, 1, pp.281-322.

2. Bauer, J.A., Thomas, T.S., Cauraugh, J.H., Kaminski, T.W., \& Hass, J. (2001). Impact forces and neck muscle activity in heading by collegiate female soccer players. Journal of Sports Sciences, 19, pp.171 - 179.

3. Dezman, Z.D.W., Ledet, E.H., \& Kerr, H.A. (2013). Neck strength imbalance correlates with increased head acceleration in soccer heading. Sports Health, 5(4), pp.320-326.

4. Elson, L.M., \& Ward, C.C. (1994). Mechanisms and pathophysiology of mild head injury. Seminars in Neurology, 14, pp.8-18.

5. Erkmen, N. (2009). Evaluating the heading in professional soccer players by playing positions. $J$ Strength Cond Res, 23, pp.1723-1728.

6. Funk, J.R., Cormier, J.M., Bain, C.E., Guzman, H., Bonugli, E., \& Manoogian, S.J. (2011). Head and neck loading in everyday and vigorous activities. Annals of Biomedical Engineering, 39(2), pp.766-776.

7. Goodman, J.C. (1994). Pathologic changes in mild head injury. Seminars in Neurology, 14, pp.1924.

8. Gronwall, D., \& Wrightson, P. (1975). Cumulative effect of concussion. Lancet, 7943, pp.995-997.

9. Hanlon, E.M., \& Bir, C.A. (2012). Real-time head acceleration measurement in girls' youth soccer. Medicine and Science in Sports and Exercise, 44(6), pp.1102-1108.

10. Kerr H., \& Riches P. (2004) Distributions of peak head accelerations during soccer heading vary between novice and skilled females. Br J Sports Med, 38, pp.650-653.

11. Levy, M.L., Kasasbeh, A.S., Baird, L.C., Amene, C., Skeen, J., \& Marshall, L. (2012). Concussions in soccer: a current understanding. World Neurosurgery, 78, pp.535-544.

12. Lipton, M.L., Kim, N., Zimmerman, M.E., Kim, M., Stewart, W.F., Branch, C.A., \& Lipton, R.B. (2013). Soccer heading is associated with white matter microstructural and cognitive abnormalities. Radiology, 268(3), pp.850-857.

13. Lynch, J.M., \& Bauer, J.A. (1996). Heading. In W.E. Garrett Jr, D.T. Kirkendall \& S.R. Coniguglia (Eds.). The U.S. Soccer Sports Medicine Book (pp.81-85). Baltimore: Williams \& Wilkins.

14. Matser, E.J.T., Kessels, A.G., Lezak, M.D., Jordan, B.D., \& Troost, J. (1999). Neuropsychological impairment in amateur soccer players. Journal of the American Medical Association, 282(10), pp.971-973.

15. Mehnert, M.J., Agesen, T., \& Malanga, G.A. (2005). "Heading" and Neck Injuries in Soccer: A Review of Biomechanics and Potential Long-Term Effects. Pain Physician, 8, pp.391-397.

16. Nauheim, R.S., Bayly, P.V., Standeven, J., Neubauer, J.L., Lewis, L.M., \& Genin, G.M. (2003). Linear and Angular Head Accelerations during Heading of a Soccer Ball. Med. Sci. Sports Exerc. 35(8), pp.1406-1412.

17. Ouellette, J. (2014). Is heading safe? Retrieved from: http://www.ayso.org/resources/safety/is_ heading_safe.aspx. 
18. Prasad, P., \& Mertz, H.J. (1993). The position of the United States delegation to the ISO Working Group 6 on the use of the HIC in the automotive environment. In S.H. Backaitis (Eds.), Biomechanics of Impact Injury and Injury Tolerances of the Head-Neck Complex PT-43 (pp.373383). Warrendale, PA.: Society of Automotive Engineers, Inc.

19. Queen, R.M., Weinhold, P.S., Kirkendall, D.T., \& Yu, B. (2003). Theoretical study of the effect of ball properties on impact force in soccer heading. Med Sci Sports Exerc, 35, pp.2069- 2076.

20. Rieder C., \& Jansen P. (2011). No Neuropsychological Consequence in Male and Female Soccer Players after a Short Heading Training. Archives of Clinical Neuropsychology, 26, pp.583-591.

21. Riches P. A (2005). Dynamic model of the head acceleration associated with heading a soccer ball. Sports Engin, 9, pp.39-47.

22. Rutherford, A., \& Stephens, R. (2007). Does football heading impair cognitive function? In W.P. Briscoe (Ed.), Focus on cognitive disorder research (pp.181-226). Hauppauge NY: Nova Science Publishers.

23. Rutherford, A., Stephens, R., \& Potter, D. (2003). The Neuropsychology of Heading and Head Trauma in Association Football (Soccer): A Review. Neuropsychology Review, 13(3), pp.153-179.

24. Rutherford, A., Stephens, R., Potter, D., \& Fernie, G. (2005). Neuropsychological Impairment as a Consequence of Football (Soccer) Play and Football Heading: Preliminary Analyses and Report on University Footballers. Journal of Clinical and Experimental Neuropsychology, 27, pp.299-319.

25. Shewchenko, N., Withnall, C., Keown, M., Gittens, R., \& Dvorak, J. (2005). Heading in football. part 2: Biomechanics of ball heading and head response. British Journal of Sports Medicine, 39(1), pp.26-32.

26. Schneider, P.G., \& Lichte, H. (1975). Untersuchungen zur groesse der krafteinwirkung beim kopfballspiel des fussballers. Sportarzut und Sportmedizin, 26(10).

27. Smodlaka V.N. (1984). Medical aspects of heading the ball in soccer. Phys Sportsmed, 12, pp.127131.

28. Sortland, O., \& Tysvaer, A.T. (1989). Brain damage in former association football players: An evolution by computed tomography. Neuroradiology, 31, pp.44-48.

29. Spiotta, A.M., Bartsch, A.J., \& Benzel, E.C. (2012). Heading in Soccer: Dangerous Play? Neurosurgery, 70, pp.1-11.

30. Stephens, R., Rutherford, A., Potter, D., \& Fernie, G. (2005). Neuropsychological impairment as a consequence of football (soccer) play and football heading: a preliminary analysis and report on school students (13 - 16 years). Child Neuropsychology, 11, pp.513-526.

31. Taha, Z., Hassan, M.H.A., Aris, M.A., \& Anuar, Z. (2013). Predicting brain acceleration during heading of soccer ball. Paper presented at the IOP Conference Series: Materials Science and Engineering, 50(1).

32. Tysvaer, A.T. (1992). Head and neck injuries in soccer: Impact of minor trauma. Sports Med, 14, pp.200-213.

33. Tysvaer, A.T., \& Storli, O. (1981). Association football injuries to the brain: A preliminary report. British Journal of Sports Medicine, 15, pp.163-166. 